\title{
Entrepreneurship, Innovation and Organizational Behaviour
}

\author{
Andrea Caputo ${ }^{1}$ and Oluremi B. Ayoko ${ }^{2}$ \\ ${ }^{1}$ University of Trento, Trento, Italy \& University of Lincoln, Lincoln, UK and ${ }^{2}$ University of Queensland, Brisbane, Australia \\ (Editor in Chief, JMO) \\ Author for correspondence: Andrea Caputo, E-mail: andrea.caputo@unitn.it
}

As far back as 1934, researchers (e.g., Schumpeter, 1934) have attested to the critical role of entrepreneurs in economic development, especially in their ability to translate technological and organisational innovation to products and services. In this respect, innovation is a key driver of entrepreneurship (Drucker, 2006). Taking a cross-disciplinary and multi-level approach, as is the nature of the Journal of Management \& Organization (JMO), this Issue (Issue 27.4) contributes to ongoing dialogues around entrepreneurship, innovation, and organizational behaviours. With this objective in mind, we bring together a collection of articles that extend the literature in areas of entrepreneurship, innovation, and organizational behavior. The authors reflect on a variety of issues such as the interface between knowledge and organizational structures, adaptive capability, emotions, organizational complexity, job crafting behaviors and context.

The first three papers in this Issue investigate knowledge and organisational structures in the context of the resource-based view and dynamic capabilities in technology firms and small and medium-sized enterprises (SMEs). Management and organisation scholars (e.g., Okhuysen \& Eisenhardt, 2002) have been long concerned with the role of organisational structures and contexts on effective knowledge creation. Especially, they were interested in teasing the connection between organisational structures and knowledge exchange and how these structures might assist in boosting innovativeness, entrepreneurship, and support superior performance outcomes. Indeed, researchers (e.g., Barney, 1991) have unveiled the role of organisational and strategic flexibility in enabling a firm to innovate, achieve and sustain competitive advantage; explaining how innovation may occur either endogenously or in response to changes in the environment. This stream of research suggests that the development of organizational capabilities and individual skills (e.g., entrepreneurship and creativity), ultimately rests on how knowledge is managed, maintained, and created. Thus, the interplay of organisational contexts and individual behaviours becomes a key area of investigation, and this is the overarching theme that is explored in our next set of papers.

The first paper titled "Pure structures or ambidextrous configurations? A grounded theory of knowledge-focused organizational design in innovative ventures" by Bodoloica and Spraggon, joins previous conversations in the JMO around informal organisational designs and their role in increasing firm agility and speedy response (see Lee, Seo, Jeung, \& Kim, 2019; Spraggon \& Bodolica, 2018). Especially, Bodoloica and Spraggon's work extends the emerging debate on structural configurations examining formal, informal, and ambidextrous configurations while determining whether and why knowledge-focused organizational designs vary across small and innovative firms. The authors adopt an inductive approach to theory building built upon multiple case studies of small innovative companies that operate in the Canadian high-tech industry, to explore the factors which explain the variation in knowledge-focused designs across firms. In this respect, analysis of these cases reveals that the pursuit of a given structural configuration results from a set of operating contingencies and a deliberate managerial effort to align firm idiosyncrasies with desired strategic outcomes. 
Context is critical in organisational studies (see Johns, 2006). The context of innovative and technology-driven firms is the subject of investigation in the next paper titled "The influence of subject heterogeneity and absorptive capacity of acquirer on innovation performance in technology-driven M\&As”. In this paper, Peng and Li extend the stream of research on resources and dynamic capabilities by discussing the influence of resource heterogeneity on innovation performance and highlighting the inhibiting effects of absorptive capacity. The authors employ factor analysis and multivariate regression to explore and measure the firms' heterogeneity on innovation performance in a sample of technological mergers and acquisitions (M\&As) of A-share listed companies in the top five high-tech Chinese industries. The authors disclose interesting results showing that slack financial resources and centralised ownership are not conducive to improving innovation performance. Similarly, governance structure was not significantly related to innovation performance following an $\mathrm{M} \& \mathrm{~A}$.

A previous issue in the JMO (27.2) was a collection of articles that examined the nexus between SMEs, Innovation and Human Resource Management (See Ayoko, 2021). The next paper, "Emotional foundations of capability development: An exploration in the SME context", authored by Kars-Unluoglu and Kevill, adds to the conversation around SMEs as published in our Issue 27.2. In a unique way, this article brings emotional foundations to bear on capability development in the SMEs. Addressing the gap in existing research, they explore how emotions of strategists enable and/or hinder capability development and then present an in-dept multiple case study analysis of SMEs from the United Kingdom and Turkey. Their results show that the strategists' emotional tensions and ambivalence have multi-faceted effects on capability development depending on the activation level of pleasant and unpleasant emotions experienced. Overall, and as echoed by Piperopoulous (2010), the firms' core competencies are embedded in the tacit knowledge and emotional intelligence of their employees.

A recent review article, Dabić, Maley, Dana, Novak, Pellegrini, \& Caputo, (2020) Dabic and colleagues (2020) highlighted the growing interest of knowledge management in SMEs (see also Soto-Acosta, Colomo-Palacios, \& Popa, 2014) with a particular emphasis on the human capital aspects of SMEs. In fact, superior human capital is noted to be paramount for SMEs performance, especially in the context of internationalization (Ruzzier, Antoncic, Hisrich, \& Konecnik, 2007). Yet, the latest research has seen a shift in analysis, moving from the entrepreneur to the firm. The three papers are a testament to this shift as they are preoccupied with organizational capabilities and how they are developed in SMEs. In this regard, Lin and Wu (2012) demonstrate that dynamic capabilities can mediate the firm's valuable, rare, inimitable and non-substitutable resources to improve performance. More studies are needed to tease out the connection between dynamic capability, knowledge and innovation in the context of SMEs.

To date, entrepreneurship research has a strong presence in the JMO (See for example, Kirkwood \& Tootell, 2008; Luke, Verreynne, \& Kearins, 2007; Mika, Warren, Foley, \& Palmer, 2017). These papers advance our understanding of entrepreneurship by examining entrepreneurial education/orientation and indigenous entrepreneurship. The next group of papers in this Issue add to the existing conversation in the JMO on entrepreneurship.

In the following paper, "Entrepreneurial education: An entrepreneurial ecosystem approach", Clark, Reboud, Toutain, Ballereau and Mazzarol look at the question, 'How can an entrepreneurial education program simultaneously create entrepreneurial knowledge, skills and competencies, as well as new ventures and jobs?' Using an exploratory case study of the entrepreneurial ecosystem developed around an innovative academic unit called The Entrepreneurial Garden (TEG) at Burgundy School of Business in Dijon, France, the paper develops a novel and comprehensive framework for enterprise and entrepreneurship education, which integrates educational interventions with new venture creation. The analysis reveals how an academic institution can be developed as an entrepreneurial ecosystem that enhances local resources and expertise, align with macroeconomic policies/priorities, and leverage partnerships and networks. Longitudinal studies of multiple cases in this area are warranted. 
The next paper, 'The nature of entrepreneurial orientation strength: The impact of shared values on firm performance' by Weinzimmer, Michel and Robin analyses how entrepreneurial orientation strength, defined as the level of agreement in the shared perceptions of entrepreneurial orientation, functions as a boundary condition in the relationship between entrepreneurial orientation and performance. With a sample of 2,000 participants and four field studies, the authors provide evidence for a valid and reliable 10-item multidimensional measure of entrepreneurial orientation, the EO-10, and identifies entrepreneurial orientation strength as a moderator in the relationship with performances. The study contributes to advancing the conversation devoted to the conceptual development and measurement of entrepreneurial orientation by bridging the past and the future of the field.

Moving from the theme of entrepreneurial orientation to that of indigenous entrepreneurship, the paper, "A study of Aotearoa New Zealand enterprises: How different are Indigenous enterprises?" by Haar, Martin, Ruckstuhl, Ruwhiu, Daellenbach, and Ghafoor, looks at the differences between Aotearoa and Māori enterprises. The study reports results from 230 indigenous enterprises which showed that Māori enterprises presented higher cultural capital in terms of employees' knowledge and skills, towards working with and respecting cultural values. No differences were found concerning human capital, relational capital, entrepreneurial culture, and organisational performance. These findings contribute to the existing debate about the distinctiveness of indigenous enterprises as published in the JMO (see Croce, 2017; Mrabure, Ruwhiu, \& Gray, 2018; Warren, Mika, \& Palmer, 2017), by suggesting that besides a culturally specific factor, Māori and non-Māori enterprises appear to be similarly enabled.

We are aware that scholars, policy makers and practitioners are increasingly focusing their attention to entrepreneurial ecosystems as fundamentally instrumental to foster resilient, circular, and sustainable economies based on entrepreneurial innovation (Audretsch \& Belitski, 2021; Pizzi, Leopizzi, \& Caputo, 2021; Wurth, Stam, \& Spigel, 2021). With entrepreneurial ecosystems, entrepreneurship scholars emphasize the context and social factors of entrepreneurship (Austin, Stevenson, Wei-Skillern, \& Wei-Skillern, 2006; Welter \& Gartner, 2016). In the ecosystem perspective, the role of entrepreneurial education is fundamental in supporting entrepreneurial orientation (Kim, Lee, Roh, \& Son, 2020; Lazzeretti \& Capone, 2020). Similarly, recent studies have started to connect entrepreneurial orientation and indigenous entrepreneurship, revealing for example, how an indigenous worldview and entrepreneurial ecosystem influences the entrepreneurial orientation of participants and this, in turn, leads to a continuum of indigenous entrepreneurial orientation (Mrabure, Ruwhiu, \& Gray, 2018).

The last four papers in this Issue further advance the conversations on organisations and organisational behaviours, investigating organisational complexity, job crafting, negotiation, and corporate social responsibility in cross-cultural contexts.

In this regard, the paper, "Re-envisioning organizational complexity using a multiple perspectives model" by Yoo highlights how contemporary organisations have become far more complex than before, requiring a high capacity for collaborations with multiple and diverse stakeholders. Presenting a single case study from an Australian Government Organization, the authors develop and apply a multiple perspective framework for the collaboration of multiple stakeholders, and to drive future organizational change. The framework support partnerships, relationships, and strategic alliances; it allows the visualisation of effective decision-making processes to foster the understanding of collaborative dynamics. The results support the use of such a multi-perspective model to address organizational complexity through the holistic integration of stakeholder perspectives and sustained knowledge flow.

Moving to one of the complexities of contemporary organisations and workplaces, Mansour and Tremblay, in their article, "How can organisations foster job crafting behaviours and thriving at work?" investigates the relation between perceived opportunity to craft and job crafting strategies, and whether these strategies are related to thriving at work. A structural equation modelling was employed on data collected from 424 accounting professionals in Canada to test the 
mediating role of job crafting between the perceived opportunity to craft and thriving. The study, one of the first to investigate these relations, shows that the perceived opportunity is positively related to increasing structural and social resources and challenging job demands. Moreover, the perceived opportunity is negatively related to decreasing hindering job demands. The authors further reveal that increasing structural and social resources enhances learning and mediates the relation between POC and vitality and learning, as do challenging job demands, whereas decreasing hindering job demands does not.

The next paper, "Distributive/integrative negotiation strategies in cross-cultural contexts: A comparative study of the USA and Italy" by Benetti, Ogliastri and Caputo, adds to the stream of studies focusing on negotiation and cross-cultural interactions previously published in the $J M O$, which covered issues related to organisational dissent and workplace freedom (Croucher, Zeng, Rahmani, \& Cui, 2018), work-life balance (Poelmans, Kalliath, \& Brough, 2008) and cultural intelligence and team conflict $(\mathrm{Hu}, \mathrm{Wu}, \& \mathrm{Gu}, 2019)$. Stemming from the study of cultural values and negotiation, which acknowledge the increased difficulties and challenges in such settings (e.g., Caputo, Ayoko, Amoo, \& Menke, 2019), this work contributes to the explanation of individual differences in negotiation strategies. Using latent class analysis on a sample of 214 accounts of negotiation behaviours faced by foreigners in Italy and the United States, the authors identify three clusters of negotiation prototypes: the typically distributive, the emotional integrative (mostly Italian), and the impersonal integrative (mostly American). The findings show the Country as a predictor for cluster membership; specific cultural traits of the two groups contribute to explain the differences in negotiation strategies and offer theoretical and practical implications about interacting with Italian and American negotiators.

A contribution to cross-cultural research is also made by the next paper, "The multi-criteria analysis of corporate social responsibility: A comparative study of Russia, Bulgaria and Serbia" authored by Stojanović, Mihajlović, Safronova, Kunev and Schulte. The work contributes to crosscultural investigations into corporate social responsibility when dealing with specific stakeholder groups. The study is conducted through a survey of SMEs from Bulgaria, Russia and Serbia, contributing to unveil corporate behaviours from firms in post-socialist states. The authors propose a multi-criterion ranking method on five dimensions: environmental, social, economic, stakeholder and voluntariness. The results show more significant differences in the attitudes of employees from different countries, rather than when the size of the company is taken into consideration.

To conclude, the articles in Issue 27.4 provide novel and original contributions to several fields of research around organisational designs, capability development, organisational complexity, negotiation, and entrepreneurship investigated across different countries and cultures. Several studies look at innovation and technology firms, unveiling idiosyncratic themes. Several studies investigated SMEs and offered important views on topics such as indigenous entrepreneurship and entrepreneurship education, providing interesting insights into the role played by culture and cultural values. Altogether, by looking at the issue through the systemic lenses, scholars may come to appreciate the importance of multi-disciplinary investigations and benefit from the linkages among a variety of approaches. While providing rigorous investigation of phenomena, each article highlights further gaps in our knowledge and offers important questions to be addressed with future research. Promising areas for new investigations may emerge as well from linking the findings of several articles presented in the Issue. In this regard, there are suggestions that digitalization may arguably be the single most important force in entrepreneurship and innovation (Berger, von Briel, Davidsson and Kuckertz, 2021). The JMO welcomes articles that can tease out the intricate connections between entrepreneurship, innovation, technology and organisational behaviors.

\section{References}

Audretsch, D. B., \& Belitski, M. (2021). Towards an entrepreneurial ecosystem typology for regional economic development: the role of creative class and entrepreneurship. Regional Studies, 55(4), 735-756. 
Austin, J., Stevenson, H., Wei-Skillern, J., \& Wei-Skillern, J. (2006). Social and Commercial Entrepreneurship: Same, Different, or Both? Entrepreneurship Theory and Practice, 30(1), 1-22. https://doi.org/10.1111/j.1540-6520.2006.00107.x

Ayoko, O. B. (2021). SMEs, innovation and human resource management. Journal of Management \& Organization, 27(1), 1-5. https://doi.org/DOI:10.1017/jmo.2021.8

Barney, J. (1991). Firm Resources and Sustained Competitive Advantage. Journal of Management, Vol. 17, pp. 99-120.

Berger, E. S., von Briel, F., Davidsson, P., \& Kuckertz, A. (2021). Digital or not-The future of entrepreneurship and innovation: Introduction to the special issue. Journal of Business Research

Caputo, A., Ayoko, O. B., Amoo, N., \& Menke, C. (2019). The relationship between cultural values, cultural intelligence and negotiation styles. Journal of Business Research, 99, 23-36. https://doi.org/10.1016/j.jbusres.2019.02.011

Croce, F. (2017). Contextualized indigenous entrepreneurial models: A systematic review of indigenous entrepreneurship literature. Journal of Management and Organization, 23(6), 886-906. https://doi.org/10.1017/jmo.2017.69

Croucher, S. M., Zeng, C., Rahmani, D., \& Cui, X. (2018). The relationship between organizational dissent and workplace freedom of speech: A cross-cultural analysis in Singapore. Journal of Management and Organization, 24(6), 776-792. https://doi.org/10.1017/jmo.2016.73

Dabić, M., Maley, J., Dana, L.-P., Novak, I., Pellegrini, M. M., \& Caputo, A. (2020). Pathways of SME internationalization: a bibliometric and systematic review. Small Business Economics, 55(3). https://oi.org/10.1007/s11187-019-00181-6

Drucker, P. (2006). Innovation and entrepreneurship. London: Harper Business.

Johns, G. (2006). The essential impact of context on organizational behavior. Academy of management review, 31(2), 386-408.

$\mathrm{Hu}, \mathrm{N} ., \mathrm{Wu}, \mathrm{J} .$, \& Gu, J. (2019). Cultural intelligence and employees' creative performance: The moderating role of team conflict in interorganizational teams. Journal of Management and Organization, 25(1), 96-116. https://doi.org/10.1017/jmo.2016.64

Kim, M. G., Lee, J.-H., Roh, T., \& Son, H. (2020). Social entrepreneurship education as an innovation hub for building an entrepreneurial ecosystem: The case of the KAIST social entrepreneurship MBA program. Sustainability, 12(22), 9736.

Kirkwood, J., \& Tootell, B. (2008). Is entrepreneurship the answer to achieving work-family balance? Journal of Management and Organization, 14(3), 285-302. https://doi.org/10.5172/jmo.837.14.3.285

Lazzeretti, L., \& Capone, F. (2020). The role of education in the entrepreneurial ecosystem: the case of Made in Italy Tuscany Academy'in the Florence fashion city. International Journal of Entrepreneurship and Small Business, 40(2), 270-290.

Lee, J. Y., Seo, Y., Jeung, W., \& Kim, J. (2019). How ambidextrous organizational culture affects job performance: A multilevel study of the mediating effect of psychological capital. Journal of Management \& Organization, 25(6), 860-875.

Luke, B., Verreynne, M.-L., \& Kearins, K. (2007). Measuring the benefits of entrepreneurship at different levels of analysis. Journal of Management \& Organization, 13(4), 312-330.

Mika, J. P., Warren, L., Foley, D., \& Palmer, F. R. (2017). Perspectives on indigenous entrepreneurship, innovation and enterprise. Journal of Management \& Organization, 23(6), 767-773.

Mrabure, R. H. O., Ruwhiu, D., \& Gray, B. (2018). Indigenous entrepreneurial orientation: A Māori perspective. Journal of Management and Organization. https://doi.org/10.1017/jmo.2018.43

Okhuysen, G. A., \& Eisenhardt, K. M. (2002). Integrating knowledge in groups: How formal interventions enable flexibility. Organization Science, 13(4), 370-386.

Pizzi, S., Leopizzi, R., \& Caputo, A. (2021). The enablers in the relationship between entrepreneurial ecosystems and the circular economy: the case of circularity. com. Management of Environmental Quality: An International Journal, ahead-of- $p$ (ahead-of-print). https://doi.org/10.1108/MEQ-01-2021-0011

Piperopoulos, P. (2010). Tacit knowledge and emotional intelligence: the 'intangible'values of SMEs. Strategic Change: Briefings in Entrepreneurial Finance, 19(3-4), 125-139.

Poelmans, S. A. Y., Kalliath, T., \& Brough, P. (2008). Achieving work-life balance: Current theoretical and practice issues. Journal of Management and Organization, 14(3), 227-238. https://doi.org/10.5172/jmo.837.14.3.227

Ruzzier, M., Antoncic, B., Hisrich, R. D., \& Konecnik, M. (2007). Human capital and SME internationalization: A structural equation modeling study. Canadian Journal of Administrative Sciences/Revue Canadienne Des Sciences de l'Administration, 24(1), 15-29.

Soto-Acosta, P., Colomo-Palacios, R., \& Popa, S. (2014). Web knowledge sharing and its effect on innovation: an empirical investigation in SMEs. Knowledge Management Research \& Practice, 12(1), 103-113.

Spraggon, M., \& Bodolica, V. (2018). A practice-based framework for understanding (informal) play as practice phenomena in organizations. Journal of Management and Organization, 24(6), 846-869. https://doi.org/10.1017/jmo.2018.30

Warren, L., Mika, J., \& Palmer, F. (2017). How does enterprise assistance support Māori entrepreneurs? An identity approach. Journal of Management and Organization, 23(6), 873-885. https://doi.org/10.1017/jmo.2017.73

Welter, F., \& Gartner, W. B. (2016). A research agenda for entrepreneurship and context. Edward Elgar Publishing.

Wurth, B., Stam, E., \& Spigel, B. (2021). Toward an entrepreneurial ecosystem research program. Entrepreneurship Theory and Practice, 1042258721998948.

Cite this article: Caputo A, Ayoko OB (2021). Entrepreneurship, Innovation and Organizational Behaviour. Journal of Management \& Organization 27, 621-625. https://doi.org/10.1017/jmo.2021.51 